\title{
LA "LEY DE LA FRONTERA": GRUPOS RUPESTRES GALAICO Y ESQUEMÁTICO Y PREHISTORIA DEL NOROESTE DE LA PENÍNSULA IBÉRICA (1)
}

\author{
“A BORDERLINE CASE": GALICIAN \\ AND SCHEMATIC ART GROUPS \\ AND THE PREHISTORY OF NW IBERIA \\ RICHARD BRADLEY (*) \\ RAMÓN FÁBREGAS VALCARCE (**)
}

Todo se pega menos la belleza.

\section{RESUMEN}

El arte rupestre puede considerarse como una forma especializada de cultura material, con un potencial de variación equivalente al de los monumentos y otras clases de artefactos. De este modo, sus características pueden reflejar la función social de esas representaciones, así como la manera de percibir el entorno por parte de los grupos humanos. Este tipo de contrastes creemos que pueden percibirse dentro del Noroeste ibérico, en una "zona de contacto" más o menos amplia en la que se superponen dos tradiciones artísticas, la ligada al Arte Esquemático vigente en gran parte de la Península y aquella, más regional, que se define como grupo de petroglifos galaicos. Las divergencias de tipo iconográfico o de emplazamiento entre las estaciones pertenecientes a uno u otro grupo se hacen eco de diferencias de más fuste por lo que respecta a las formas de asentamiento, explotación y definición del territorio entre las áreas Mediterránea y Atlántica peninsulares.

(1) El trabajo que aquí presentamos es una versión corregida del artículo publicado en el Oxford Journal of Archaeology (17-3-1998: 287-308), titulado "Crossing the border: contrasting styles of rock art in the Prehistory of North-West Iberia".

(*) Universidad de Reading. Department of Archaeology. RG62AA Reading, Inglaterra. E-mail: r.j.bradley@reading.ac.uk.

(**) Universidade de Santiago de Compostela. Departamento de Historia 1. Facultade de Xeografía e Historia. 15704 Santiago de Compostela. Correo electrónico: phfabreg@usc.es.

El artículo fue remitido en su versión final el 14-X-98.

\begin{abstract}
Rock art can be regarded as a specialised form of material culture, and at the regional scale it may have exhibited as much diversity as monuments and portable artefacts. Its character might also have changed in relation to different practices and different ways of perceiving and using the landscape. Such contrasts can be identified in the prehistoric rock art found on either side of the modern border between Portugal and Spain and may be related to much broader currents in Iberian archaeology, extending from the Atlantic to the West Mediterranean.
\end{abstract}

Palabras clave: Arqueología espacial. Arte Esquemático. Petroglifos galaicos. Edad de los Metales.

Key words: Spatial archaeology. Schematic Art. Galician petroglyphs. Metallurgy.

\section{NORTE CONTRA SUR}

La Península Ibérica ocupa un lugar muy especial en las síntesis de arqueología europea, debido al papel que la primera ha jugado en una multitud de fenómenos que van desde la aparición de las sepulturas megalíticas al comercio del vino en el mundo romano (Fig. 1). No obstante su situación geográfica, en el extremo suroccidental del continente, plantea en ocasiones problemas para integrar 


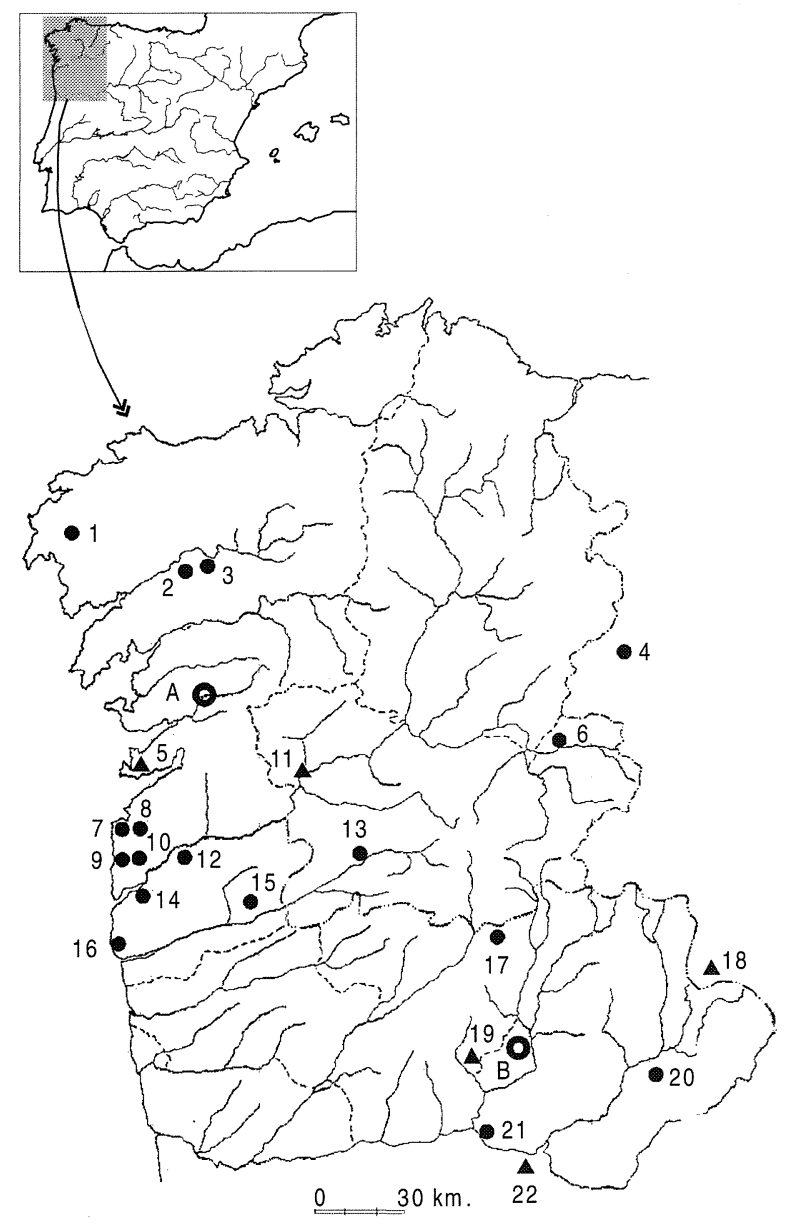

Fig. 1. Localización del área de estudio (sombreada) dentro de la Península Ibérica y principales yacimientos o grupos de éstos analizados en el curso del proyecto de investigación o aludidos en este texto. Las estaciones rupestres están indicadas mediante círculos y los asentamientos con triángulos. A: área de Campo Lameiro; B: complejo de Serra dos Passos / Santa Comba; 1: Pedra Ancha (Dumbría); 2: Peneda Negra (Ames); 3: Monte Pedroso (Santiago); 4: Peña Pineda (Vega de Espinareda); 5: Mesa de Montes (Cangas); 6: Villamartín de Valdeorras; 7: Os Campos (Baiona); 8: Auga da Laxe (Gondomar); 9: Laxe dos Cebros (Oia); 10: Monte Tetón (Tomiño); 11: Outeiro das Minas (Ribadavia); 12: Monte da Laje (Valença); 13: Bande; 14: Laxe das Fogaças (Caminha); 15: Gião (Arcos deValdevez); 16: Farol de Montedor (Viana do Castelo); 17: Tripe (Chaves); 18: El Pedroso (Trabazos); 19: Crasto de Palheiros (Murça); 20: Penas Roias (Modagouro); 21: Cachão da Rapa (Carrazeda deAnsiães); 22: Castelo Velho (Vila Nova de Foz Côa). El grupo galaico está integrado por los yacimientos de Campo Lameiro y los puntos 1-3. 5-6 y 13. El "área de contacto" está representada por los puntos 7 a 12 y 14. El arte esquemático en forma de pintura o grabado está presente en los yacimientos 4, 15-18,20-21 y zona de Passos/Santa Comba. los acontecimientos ibéricos en una narrativa más general. Por su parte, la arqueología de la Fachada Atlántica se encuentra igualmente en una situación peculiar, pues la región ha constituído una de las grandes rutas de navegación del mundo prehistórico y al tiempo se encuentra en una posición marginal en el conjunto de Europa. De este modo, cuestiones como el arte megalítico, el campaniforme marítimo o el denominado Bronce Atlántico se configuran como sucesos independientes, separados los unos de los otros por períodos más o menos amplios en los que el frente atlántico de Europa deja de ser objeto de atención por parte de los estudiosos.

La situación descrita en el párrafo precedente afecta de forma muy especial a la Península Ibérica, puesto que es precisamente aquí donde las rutas mediterránea y atlántica confluyen y con ellas entran en contacto objetos e ideas de muy distinto origen. Esta circunstancia se hace especialmente patente durante el Calcolítico y la Edad del Bronce, etapas en lás que las secuencias regionales de España y Portugal ocupan una posición relevante en las síntesis de prehistoria europea (Coles y Harding, 1979: 214-39). La causa principal de esta preeminencia estriba en la existencia en el Sureste de un desarrollo cultural que incluye formas fortificadas de asentamiento, enterramientos de gran riqueza y la práctica temprana de la metalurgia. Algunos de estos rasgos se hallan presentes igualmente en la costa atlántica peninsular, especialmente en las inmediaciones del estuario del Tajo (Chapman, 1991) y, de forma más atenuada, en el Norte de Portugal (S. Jorge, 1993; Sanches, 1996a). Se ha discutido con cierta amplitud el alcance y la naturaleza de las relaciones que existirían entre la Península y zonas tan lejanas como Irlanda (Harrison, 1974; Eogan, 1990; Almagro, 1995), pero este énfasis en los vínculos a larga distancia creemos que provoca un desenfoque del problema: dos mundos parecen haber entrado en contacto durante el período aludido, pero los elementos que deben caracterizar cada una de esas esferas están todavía mal definidos, ¿debemos limitarnos a la evidencia suministrada por el registro artefactual o bien podemos reconocer comportamientos diferentes en cuanto a la ocupación y demarcación del territorio?

\section{LOS PETROGLIFOS GALLEGOS EN EL PAISAJE}

$\mathrm{El}$ arte rupestre al aire libre de Galicia nos proporciona una herramienta ideal para empezar a con- 
testar la pregunta lanzada en el apartado previo, pues una serie de trabajos en los últimos años han versado sobre la integración de esta manifestación artística en el marco más genérico de las pautas de asentamiento de los grupos responsables de su ejecución (Peña y Rey, 1993; Bradley et alii, 1995; Santos, 1996).

La máxima concentración de grabados se da en un área que se extiende desde la costa hacia el interior en una distancia de $60 \mathrm{~km}$. como máximo (Vázquez, 1990; Costas y Novoa, 1993). Esta es una región de marcados contrastes bioclimáticos a lo largo del año, los cuales pueden haber inducido migraciones animales hacia las tierras más altas durante la sequía estival. Muy a menudo las mayores concentraciones de petroglifos se dan a lo largo de rutas naturales que hombres y animales habrían seguido en sus desplazamientos del valle a los montes. Estas manifestaciones artísticas abundan igualmente en torno a cuencas húmedas ( $b$ rañas) donde a su vez se localizan frecuentemente asentamientos coetáneos. Estos últimos son todavía mal conocidos pero suelen presentar restos materiales encuadrables en cronologías bastante amplias, si bien el carácter de cada una de las ocupaciones no parece encajar con un patrón sedentario a largo plazo. Lasbrañas mantienen su humedad en los meses más secos del año y por ello proporcionan unos excelentes lugares de pasto, pero al mismo tiempo las zonas más a salvo del encharcamiento son aptas para la agricultura y no hay que olvidar la recolección y la caza en el entorno menos antropizado, si bien la importancia de esta última actividad parece claramente exagerada en las representaciones rupestres, en las que el ciervo predomina ampliamente entre los motivos animalísticos (Bradley et alii, 1995; Méndez, 1998).

En el importante conjunto rupestre en torno a Campo Lameiro (Pontevedra) (Fig. 2) la ubicación de las rocas grabadas sigue unas pautas muy sistemáticas, pues con poca excepciones se escogen afloramientos escasamente visibles, distribuidos en las inmediaciones de brañas o a lo largo de las rutas que comunican dichas formas fisiográficas. Las figuras se trazan sobre superficies aplanadas y dejan de distinguirse en cuanto el observador se distancia unos pocos metros $\mathrm{y}$, por su parte, el dominio visual desde los paneles es generalmente reducido (Bradley et alii, 1995; Criado et alii, e.p.). A una escala más de detalle se observan diferencias iconográficas en función del emplazamiento preciso de los grabados y así aquéllos que se encuentran junto a rutas de tránsito poseen un repertorio de
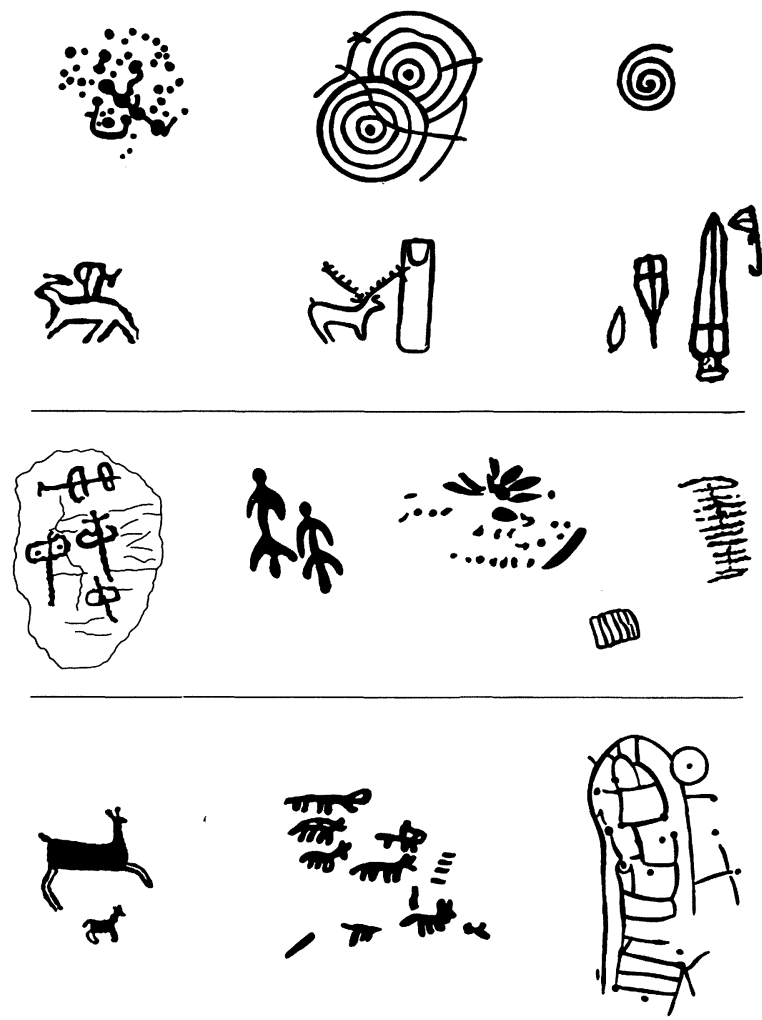

Fig. 2. (Arriba) Motivos más frecuentes del repertorio de los petroglifos galaicos; (centro) temas presentes en elArte Esquemático del Noroeste ibérico; (debajo) representaciones halladas en la zona de solapamiento entre ambos grupos artísticos.

motivos más simple que los inmediatos a las $\mathrm{bra}$ ñas o los situados en la periferia de las áreas ocupadas más intensamente. En este sentido resulta plausible la idea de que uno de los papeles del arte al aire libre fuese el de señalizadores de diferentes partes del paisaje, así como de los derechos que un grupo particular reclamase sobre éstas.

Algunas estaciones rupestres escapan a las pautas descritas en el párrafo anterior: se trata básicamente de representaciones de armas metálicas o de ciervos con grandes cornamentas. Estos últimos se diferencian de otros motivos animales por sus mayores dimensiones y el exagerado tamaño de su cuerna. Los paneles se emplazan en los límites superiores de las áreas de asentamiento y en ocasiones poseen un amplio control visual. Si tenemos en cuenta que en su estado natural los ciervos suelen situarse durante la berrea anual en puntos elevados del terreno desde los cuales desafían a otros machos por el acceso preferencial a las hembras, los rasgos iconográficos y espaciales de ese particular grupo de grabados animalísticos hacen plausible pensar en 
la complejidad de su significado, girando quizás en torno al papel de una genérica agresividad masculina en la definición metafórica -o no tanto- del control exclusivo de un territorio determinado (Bradley, 1997: 200-3).

Por su parte, los petroglifos de armas consisten básicamente en representaciones de puñales y alabardas (Peña, 1979; Costas y Novoa, 1993) y comparten algunos de los rasgos mencionados en el caso de los grandes cérvidos. Se localizan en la periferia de las áreas de explotación preferencial y desde ellos se obtiene a menudo una buena panorámica de tierras a baja altura, situadas a cierta distancia. En ocasiones parecen vincularse con rutas que unen distintos focos de asentamiento mientras que en otras comparecen en posiciones más aisladas (Santos, 1996). A veces (v.g. Auga da Laxe 1 o Pedra Ancha) se utilizan afloramientos muy conspicuos y además los grabados se efectuan sobre superficies inclinadas, de tal forma que las imágenes confrontan al observador que se aproxima a la roca (Bradley et alii, 1995; Bradley, 1997; Peña y Rey, 1998). Más recientemente se han observado las concomitancias entre los depósitos metálicos del Bronce inicial y los petroglifos en aspectos como la localización espacial o la composición ergológica de unos y otros (Bradley y Fábregas, 1995; Bradley, 1998: 249-50).

Ya para terminar, podemos afirmar que, con las excepciones citadas, el grupo galaico de arte rupestre reune una serie de rasgos comunes, el primero de ellos el manifestarse en una región y un período caracterizados por la existencia de asentamientos abiertos, carentes de estructuras defensivas e implicando una forma de vida todavía no estrictamente sedentaria. Los grabados se integran perfectamente en una forma de vida y de explotación del territorio en que la movilidad jugaba un papel todavía importante, aunque lejos desde luego de las pautas propias de sociedades cazadoras-recolectoras. Las rocas con petroglifos no se hurtaban a la vista, pues se emplazaban en las inmediaciones de lugares de tránsito o de cuencas húmedas frecuentemente utilizadas por esas comunidades. Sin embargo, a pesar de formar una parte importante del sistema de apropiación del paisaje, las estaciones rupestres evitan casi siempre los afloramientos más destacados del entorno.

\section{EN EL LÍMITE}

Las características del grupo galaico de arte rupestre tienden a modificarse a medida que nos acer- camos a los límites de su área de distribución: en general el repertorio iconográfico se simplifica hasta quedar limitado a sus expresiones más abstractas (combinaciones circulares y cazoletas), pero en cambio su emplazamiento se hace más diverso. Ciertamente, sigue habiendo estaciones que se vinculan a caminos o cuencas húmedas y que persisten en la utilización como soporte de rocas apenas visibles, pero a su lado comienzan a proliferar grabados en superficies desde las que se dominan amplias panorámicas o se seleccionan roquedos más conspicuos (Bradley y Fábregas, 1996). Al mismo tiempo la localización de las figuras en los paneles apunta a que estas manifestaciones artísticas podrían haber sido usadas de forma distinta: en una serie de casos parece como si la visión del afloramiento rocoso desde una posición inferior fuese tan importante como la panorámica que se puede contemplar desde los mismos petroglifos. Así sucede en la Peneda Negra (Ames, A Coruña), un enorme bloque granítico con paredes casi verticales, en cuya cima se grabaron unos pocos motivos abstractos, de tal forma que cualquiera que se situase junto a las figuras se vería realzado como si se hallase sobre un escenario. Una situación semejante se da en otra estación próxima, la de Monte Pedroso (Santiago de Compostela), donde se trazaron unas combinaciones circulares en una reducida repisa horizontal, oculta en el flanco de un gran afloramiento (Acuña et alii, 1987) (Lám. I), una disposición que volvemos a encontrar mucho más al Norte en el petroglifo de Chamorro (Ferrol) (GATT, 1996).

Hacia el Sur de Galicia documentamos cambios aún más llamativos, que afectan a las pautas de asentamiento por un lado, y a la ubicación e iconografía

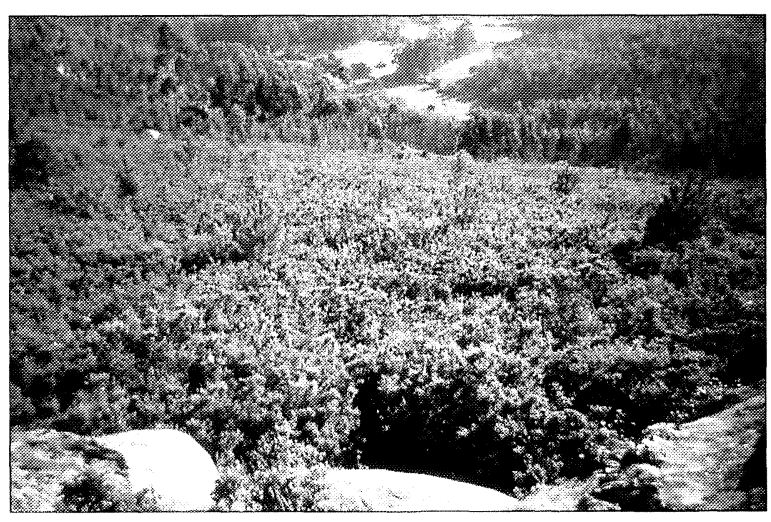

Lám. I. Panorámica desde el petroglifo de Monte Pedroso (Santiago de Compostela). 
del arte rupestre por otro. En cuanto al primer aspecto se observa la existencia de hábitats situados en lugares elevados, como los de Mesa de Montes (Cangas, Pontevedra) o As Minas (Ribadavia, Ourense) que denotan una mayor preocupación defensiva o de control territorial y si bien no se han detectado obras de fortificación en ninguno de ellos, su peculiar localización o la riqueza y abundancia de la cultura material recuperada, incluyendo en algún caso artefactos de cobre, apuntan a una dinámica de ocupación del territorio menos móvil que en las áreas nucleares del grupo galaico de arte rupestre (Fábregas y Ruíz-Gálvez, 1997; Carballo et alii, e.p.). Las características de esos asentamientos muestran en cambio concomitancias con los poblados localizados recientemente en el Norte de Portugal, varios de ellos fortificados ya desde comienzos del III milenio (Jorge, 1994; Sanches, 1996).

El intensivo trabajo de catalogación llevado a cabo en los últimos años en el área que abarca desde la ría de Vigo hasta el Baixo Miño no sólo ha permitido aumentar exponencialmente el número de estaciones rupestres conocidas sino también documentar su personalidad con relación al "área clásica" en torno a Campolameiro (Costas e Hidalgo, 1995; Bradley y Fábregas, 1996) (Fig. 3). Así, en

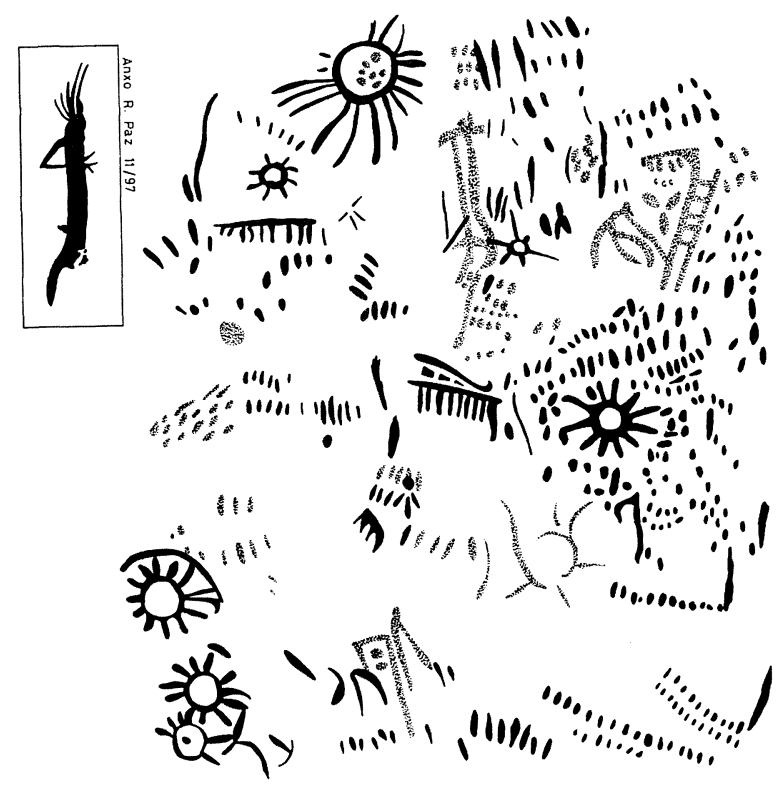

Fig. 3. Panel pintado en Cueva del Cristo, Las Batuecas. Los motivos dibujados en negro corresponden a los pintados en rojo; los rayados son de color marrón. El inserto recoge un detalle de las pinturas de Cueva de la Umbría del Canchal del Cristo, asimismo en Las Batuecas (según Breuil, 1933). contraste con la última zona mencionada, se hace más común la selección de afloramientos prominentes con amplias panorámicas a larga distancia y también aparecen con frecuencia grabados en terrenos relativamente elevados. Estos rasgos diferenciados no vienen impuestos por constreñimientos del entorno sino que parecen obedecer más bien a una actuación intencional.

Pero no sólo se advierten cambios en los criterios de selección de las rocas que debían ser grabadas, también se constatan modificaciones de orden formal como es el carácter más plástico de las decoraciones abstractas: efectivamente, en vez del énfasis habitual en el empleo de superficies horizontales, nos encontramos con algunas estaciones rupestres en las que las insculturas tienden a cubrir la totalidad de la roca, abarcando incluso el propio contorno de ésta, como sucede en Tapada de Ozão (Valença, Viana do Castelo). Otro caso paradigmático de este fenómeno se da en el Monte Tetón (Tomiño, Pontevedra), donde la cúspide redondeada de un gran afloramiento aparece completamente decorada mediante una excepcional combinación de 17 círculos concéntricos, con un diámetro total superior a los 3 m. (Costas et alii, 1989) (Lám. II). El efecto de tan inusual disposición sería resaltar el culmen del roquedo de tal forma que actuase como un estrado para cualquiera que se hallase sobre él.

Las representaciones de armas muestran también algunos cambios en la zona que estamos considerando: por un lado éstas son algo más frecuentes que en otras comarcas y por otro, el tamaño de las imágenes individuales aumenta, hasta el punto que las dos estaciones más meridionales con esta clase de motivos (Auga da Laxe I -Gondomar, Ponteve-

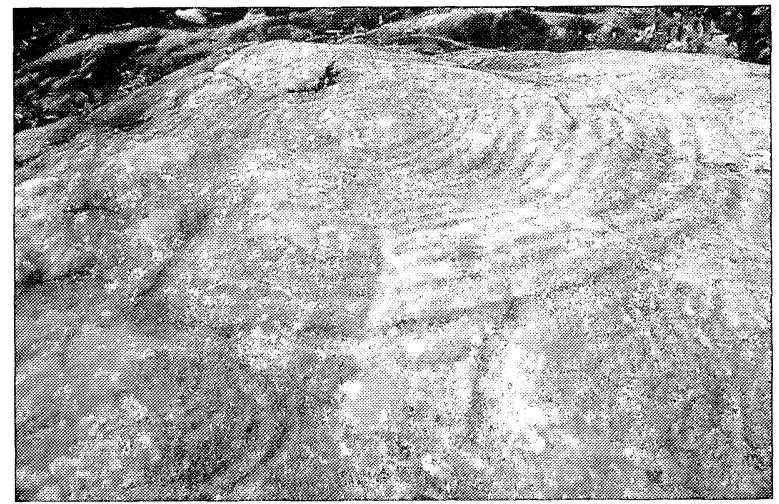

Lám. II. Gran combinación circular de Monte Tetón (Tomiño, Pontevedra), aprovechando la protuberancia natural de la roca. 
dra- y Monte da Laje - Valença, Viana do Castelo-) exhiben igualmente las mayores armas conocidas hasta el momento. En el primer caso, la espada n. ${ }^{\circ} 1$ mide 2' 4 m. de longitud, mientras en el segundo el puñal tiene más de un metro de largo (Hidalgo y Costas, 1984-85; Silva y Cunha, 1986).

Considerada en su conjunto, la evidencia manejada sugiere que en los límites meridionales del área de distribución de los petroglifos galaicos las actitudes ante el paisaje natural pueden haber cambiado: los grabados tienden a ocupar rocas más prominentes, a veces emplazadas en lugares elevados; los motivos ya no se limitan a la superficie plana de la piedra sino que en ocasiones se amoldan a los contornos de ésta, para dar una impresión más tridimensional. Durante el mismo período se constata la ocupación de algunos cerros con buenas condiciones naturales de defensa, una práctica que contrasta con el carácter mucho más críptico de los hábitats contemporáneos de comarcas más norteñas.

Un segundo aspecto que conviene discutir con cierta profundidad es el del particular repertorio iconográfico observable en las estaciones rupestres próximas a la frontera galaico-portuguesa y muy particularmente en el área del Baixo Miño, donde ya señalamos que se han efectuado descubrimientos importantes durante la última década (Costas et alii, 1991; Costas e Hidalgo, 1995). En términos generales esta zona se distingue del "área clásica" por la menor presencia de figuraciones animales, el predominio de los motivos geométricos y la relativa importancia de las representaciones de armas. También se conoce un cierto número de motivos antropomorfos y en " $\Phi$ " que presentan grandes semejanzas con temas habituales en el Arte Esquemático peninsular, pero que en nuestro caso plantean dudas en cuanto a su cronología prehistórica.

Las figuraciones animales en el Baixo Miño poseen unas características específicas en lo referente a morfología y técnica de elaboración (Bradley y Fábregas, 1996; Costas et alii, 1997b). Se distinguen de las clásicamente galaicas por su gran sencillez, diseñando el animal con una simple línea para cabeza, cuerpo y cola, a la que se suman otros trazos verticales figurando las extremidades (Lám. IIIa y IIIb), lo que da un resultado a menudo próximo a los pectiniformes del Arte Esquemático, presentes en el noreste de Portugal y región occidental de Castilla-León, donde estos motivos se encuentran habitualmente pintados, una técnica que quizás imiten los zoomorfos de Auga dos Cebros (Oia, Pontevedra), grabados en una inusual

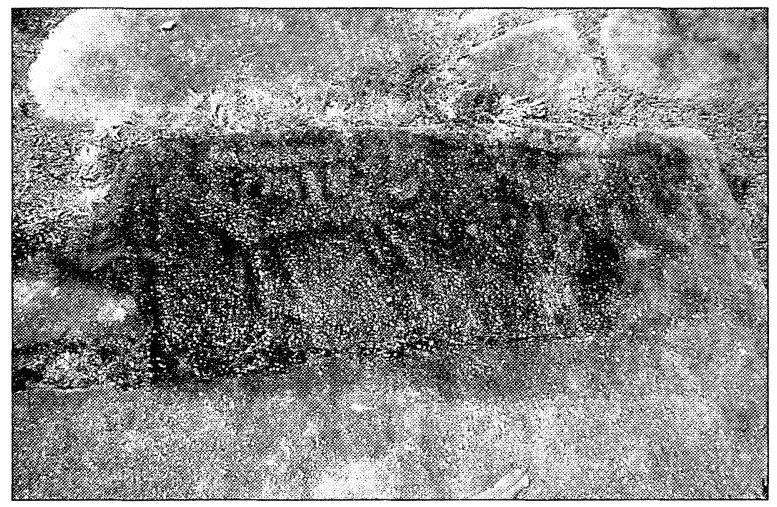

Lam. IIIA. Zoomorfos esquemáticos en un pequeño panel de Os Campos (Baiona, Pontevedra).

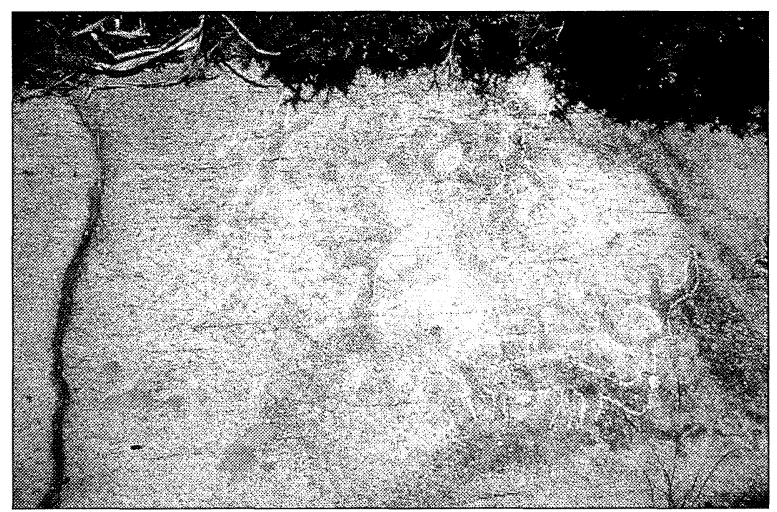

Lam. IIIB. Antropomorfos y animales esquemáticos en la Pedra do Cazador (Oia, Pontevedra).

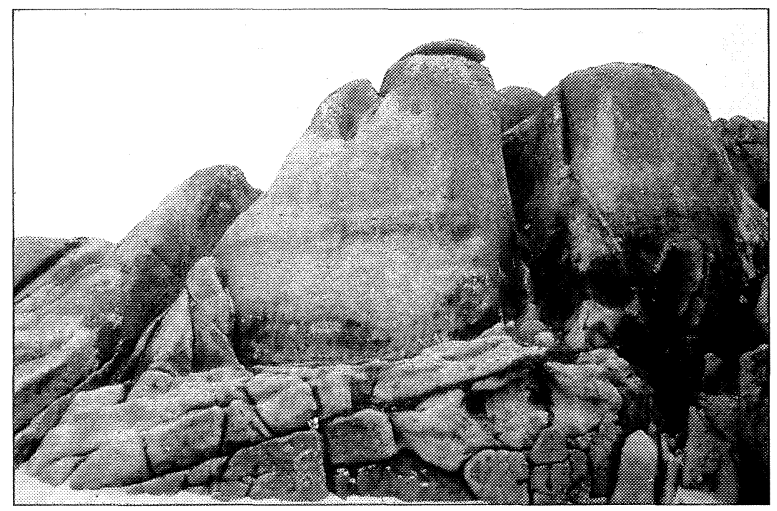

Lam. IIIC. Estación rupestre de Farol de Montedor (Afife). Los grabados esquemáticos se concentran en la base de la roca triangular en el centro de la imagen.

técnica de bajorrelieve (Costas et alii, 1995). No obstante en esta región también se conocen animales trazados de forma seminaturalista, más acorde 


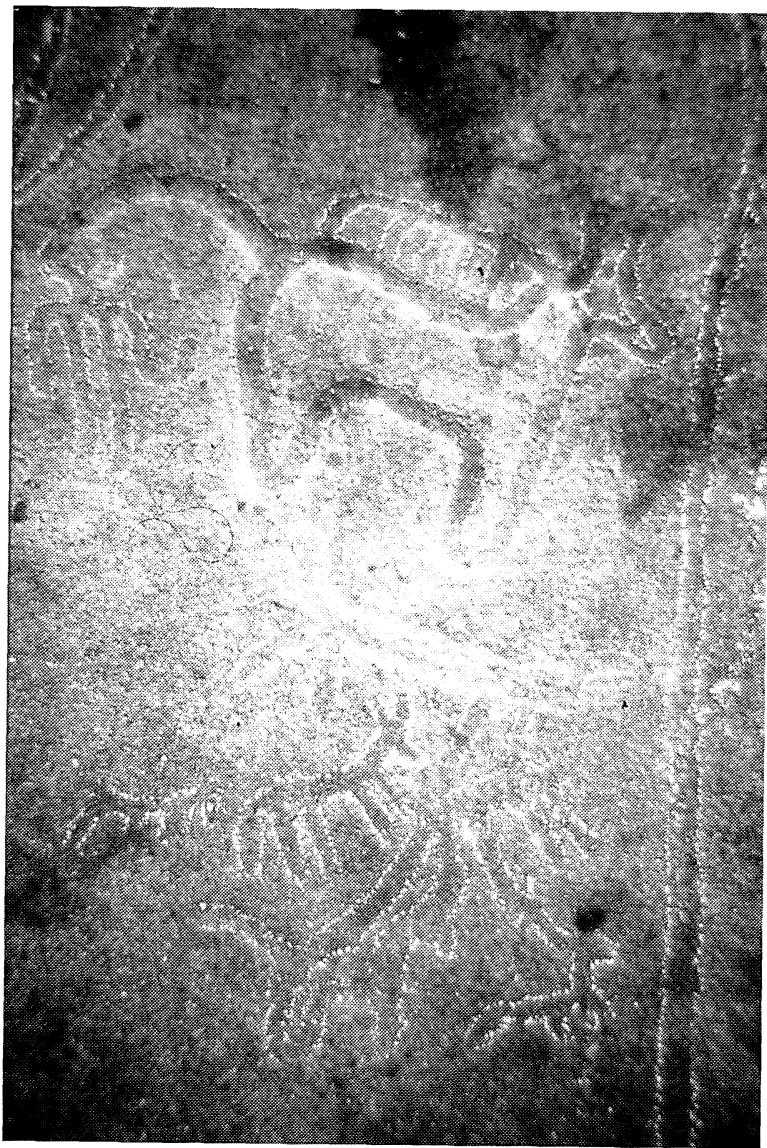

Lám. IV. Animales ejecutados siguiendo las pautas del grupo galaico y del arte esquemático en el panel central de Laje das Fogaças (Caminha, Viana do Castelo).

con el canon de los petroglifos galaicos, e incluso paneles como el de Laje das Fogaças (Caminha, Viana do Castelo) reunen figuras diseñadas en ambos subestilos (Lám. IV). Esta combinación de imágenes siguiendo convenciones de estilo diferentes no es un caso aislado y volvemos a encontrarlo en Monte da Laje (Valença, Viana do Castelo), una roca con grabados típicamente galaicos (círculos concéntricos, cazoletas, puñales), así como varios idoliformes, uno de los cuales presenta una forma rectangular absidada e interior segmentado. Dicho motivo posee grandes similitudes formales con figuras documentadas en el arte esquemático, especialmente en el Norte de España y la Meseta, vinculándose a un conglomerado simbólico más vasto y de filiación meridional, en el que se integrarían las placas alentejanas (Bueno, 1992; Fábregas y Penedo, 1994).

A lo largo de su área de distribución el Arte Es- quemático suele aparecer sobre superficies verticales, una pauta que también se advierte en los ejemplos trasmontanos y que contrasta con la preferencia, ya comentada, de los grabados galaicos por los paneles más o menos horizontales. La mayoría de los grabados en la zona del Miño se atienen a esta última pauta, con algunos rasgos específicos a los que hemos aludido más arriba. Sin embargo, hay dos estaciones que se alejan por completo de esa regla, las de Farol de Montedor (Afife, Viana do Castelo) y Os Campos (Baiona, Pontevedra) (Costas et alii, 1991; Bradley y Fábregas, 1996). La primera se localiza en plena línea costera y se trata de un gran afloramiento granítico en una de cuyas paredes verticales se han efectuado grabados de animales, exclusivamente esquemáticos (Lám. IIIc). Por su parte, Os Campos constituye un conjunto bastante amplio del que forman parte tanto rocas con representaciones del grupo galaico como otras de estilo esquemático. Los primeros siguen las pautas de localización de ese grupo y se emplazan junto a un camino que conduce hacia una zona más alta y húmeda que está presidida por un enorme roquedo sobre el que se han grabado numerosos zoomorfos esquemáticos aprovechando un lienzo casi vertical y unos pocos más al pie de la peña. Parece bastante claro que este bloque rocoso retuvo su importancia simbólica durante bastante tiempo, pues también se encuentran en el mismo panel figuras que posiblemente sean más modernas, como una esvástica flameada levógira. Desde la cima aplanada de este batolito se divisan los dos paneles con círculos concéntricos, emplazados en ambos extremos de Os Campos y, a su vez, contemplado desde una posición inferior el panel grabado ofrece una impresionante visión, situado al lado de una repisa que podría haber constituido un marco idóneo para llevar a cabo actividades ceremoniales.

\section{EL ARTE ESQUEMÁTICO EN EL PAISAJE}

En este último apartado continuaremos nuestro viaje imaginario a campo traviesa, examinando una serie de yacimientos encuadrables en el grupo esquemático y situados más hacia el Este del área que hemos estado analizando hasta ahora. En primer lugar consideraremos el emplazamiento de esas estaciones, así como su relación con los asentamientos y, por último, reflexionaremos acerca de la significación genérica de las imágenes representadas. 
A primera vista parece claro que el emplazamiento del arte esquemático es muy diferente al de las estaciones del grupo galaico, sin que ello pueda atribuirse a las características topográficas locales. El primero, sea en forma de grabado o pintura, suele aparecer generalmente sobre paneles verticales emplazados en abrigos o covachas, en zonas de relieve escarpado. Estas características se cumplen en un grupo de yacimientos situados cerca de los actuales límites administrativos de Galicia, como Peña Pineda (Vega de Espinareda, León), El Pedroso (Trabazos, Zamora) o el siempre creciente grupo de estaciones esquemáticas de Tras-os-Montes (Esparza, 1977; Gutiérrez y Avelló, 1986; Sanches, 1996a). Rara vez se encuentran estas representaciones en lugares fácilmente accesibles, sino más bien en puntos elevados con amplio dominio visual y quizás no sea casual que en ellos o en sus inmediaciones se hayan instalado eremitorios en tiempos históricos.

Si nos alejamos del cuadrante noroccidental en dirección al importante núcleo esquemático salmantino y extremeño podemos reforzar las observaciones anteriores: en Las Batuecas (Salamanca) los paneles pintados se emplazan en lugares de difícil acceso, dominando una escarpada garganta (Breuil, 1933; Bécares, 1991) (Lám.V). Aunque es perfectamente posible que esos puntos fuesen visitados en el curso de expediciones de caza o atendiendo al ganado, algunos de ellos están tan alejados que ello parece poco factible. Igualmente es poco probable que esos yacimientos sirviesen como punto de observación para controlar los movimientos de animales o seres humanos, pues su remota posición respecto al fondo del valle haría poco práctica esa clase de vigilancia. Por otra parte, no sólo es muy difícil acceder a algunas de las superficies pintadas, sino que además el espacio disponible junto a ellas no permite congregar a mucha gente de cada vez. Un reciente trabajo sobre el arte esquemático en Las Villuercas (Cáceres) (García Arranz, 1990) refuerza la noción de que estos lugares estaban dotados de un carácter especial: de nuevo encontramos las pinturas en puntos bastante inaccesibles o incluso peligrosos de alcanzar, pero además se constata una selección de las superficies a decorar atendiendo a una coloración particular de la roca (de un tono rojo amarillento). La existencia de ciertos criterios estéticos a la hora de escoger los puntos concretos que habrían de ser pintados se documenta también en el Norte de Portugal, donde parece haber una preferencia por los soportes en los

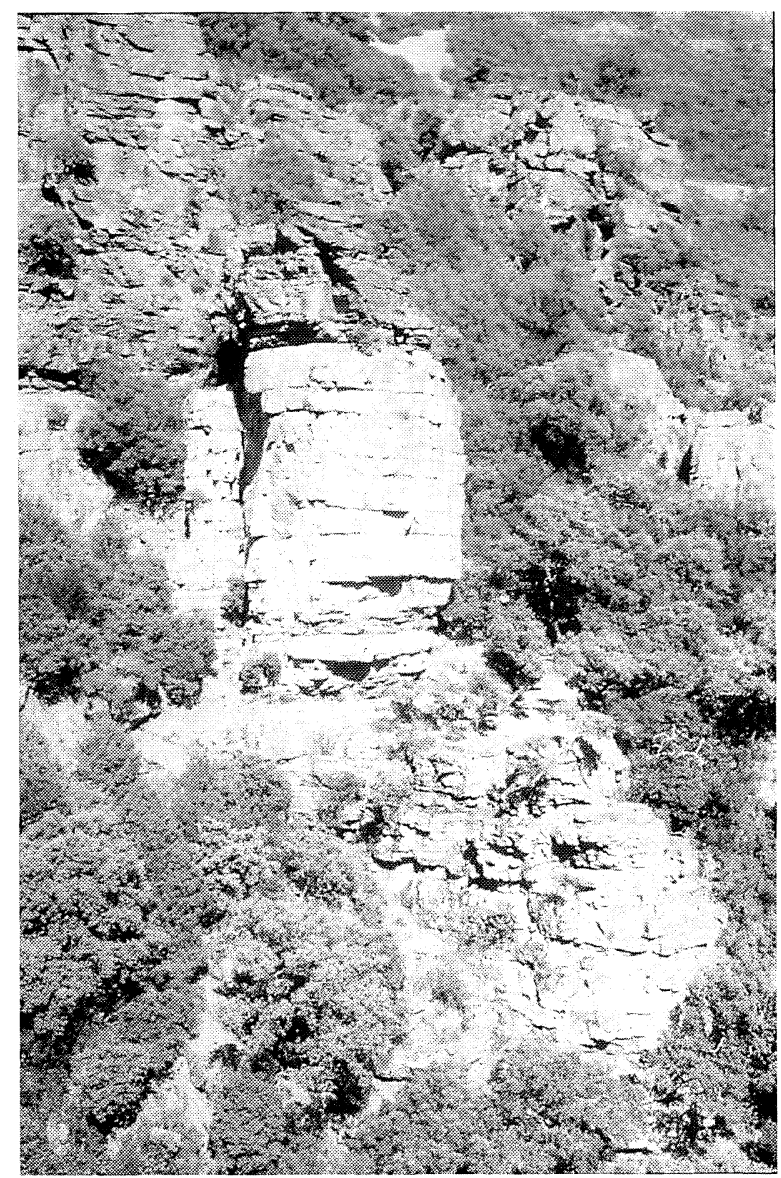

Lám.V. Aspecto de una de las zonas con abrigos pintados de Las Batuecas (Salamanca).

que aparecen de forma abundante inclusiones de cuarzo lechoso (Lara Alves, comunicación personal Universidad de Reading).

A un nivel más subjetivo, da la impresión de que el Arte Esquemático suele vincularse a formas de relieve espectaculares y el mismo emplazamiento del arte parece reforzar el carácter extraordinario de esos lugares. Así, en Las Villuercas algunas de las imágenes más complejas se distribuyen exclusivamente por el techo de las oquedades y algo semejante se documenta en el conjunto trasmontano de Regato das Bouças (Sanches, 1996b), pues es en dicho lugar donde aparece una mayor variedad de representaciones y de pigmentos. De hecho, el abrigo es tan bajo que las pinturas sólo pueden ser vistas recostándose en el suelo y dado que algunas de ellas se prolongan por fuera de la propia boca de la covacha, en pleno precipicio, su ejecución habría conllevado un cierto riesgo para el autor o autores. También en Las Batuecas encontramos que algunos de

T. P., 56, n. ${ }^{\circ} 1,1999$ 
los más elaborados paneles sólo eran accesibles pasando a través de estrechas repisas abriéndose directamente al abismo y aún considerando como probable que las gentes responsables de su ejecución tuviese un pie más firme que los autores de este trabajo, lo cierto es que ese tipo de localización haría muy sencillo el control del acceso a las zonas pintadas.

La cuestión de la accesibilidad de los conjuntos esquemáticos resulta especialmente interesante si tomamos en consideración las evidencias de ocupación de esos lugares, para lo cual tenemos un buen punto de partida en los trabajos desarrollados por M.J. Sanches (1996b, 1997) en las serranías de Santa Comba/Os Passos (Bragança). En esta zona se conoce un buen número de oquedades, algunas de las cuales fueron pintadas mientras otras muestran señales de habitación pero sólo en un caso (Buraco da Pala) se dan ambas circunstancias. La excepcionalidad de este solitario ejemplo viene reforzada por el carácter especial de las actividades llevadas a cabo en el yacimiento durante la última fase de su prolongada existencia (circa mediados del III milenio ANE) que no permiten etiquetarlo como un contexto doméstico sin más.

Algunos de los abrigos decorados en Santa Comba/Os Passos se emplazan en las inmediaciones de hábitats al aire libre (Sanches, 1996b), algo que también sucede en el caso de El Pedroso (Zamora) donde los grabados aparecen en una oquedad situada en la empinada ladera de un altozano donde se alza un poblado calcolítico fortificado (Esparza, 1977; Delibes et alii, 1995) (Lám. VI). En este último caso, si bien el abrigo es visible desde el terreno situado cuesta abajo, no se puede divisar desde la cima de la colina donde se halla el asentamiento. Esta misma circunstancia se repite en sendas estaciones esquemáticas trasmontanas (Cachão da Rapa y Penas Roias) (Jorge y Jorge, 1991) en una posición relativamente excéntrica respecto de otros tantos poblados en altura y sin una ruta directa entre unas y otros.

El repertorio iconográfico delArte Esquemático presenta dos características que pueden arrojar alguna luz a la hora de interpretar las estaciones con esta clase de representaciones. Uno de estos rasgos es la llamativa coincidencia con el elenco de motivos presentes en la decoración megalítica (Bueno y Balbín, 1992). El contexto de este último grupo artístico es muy revelador, pues se asocia normalmente con sepulturas de corredor en las que la decoración se aplica sobre todo en la parte posterior de la

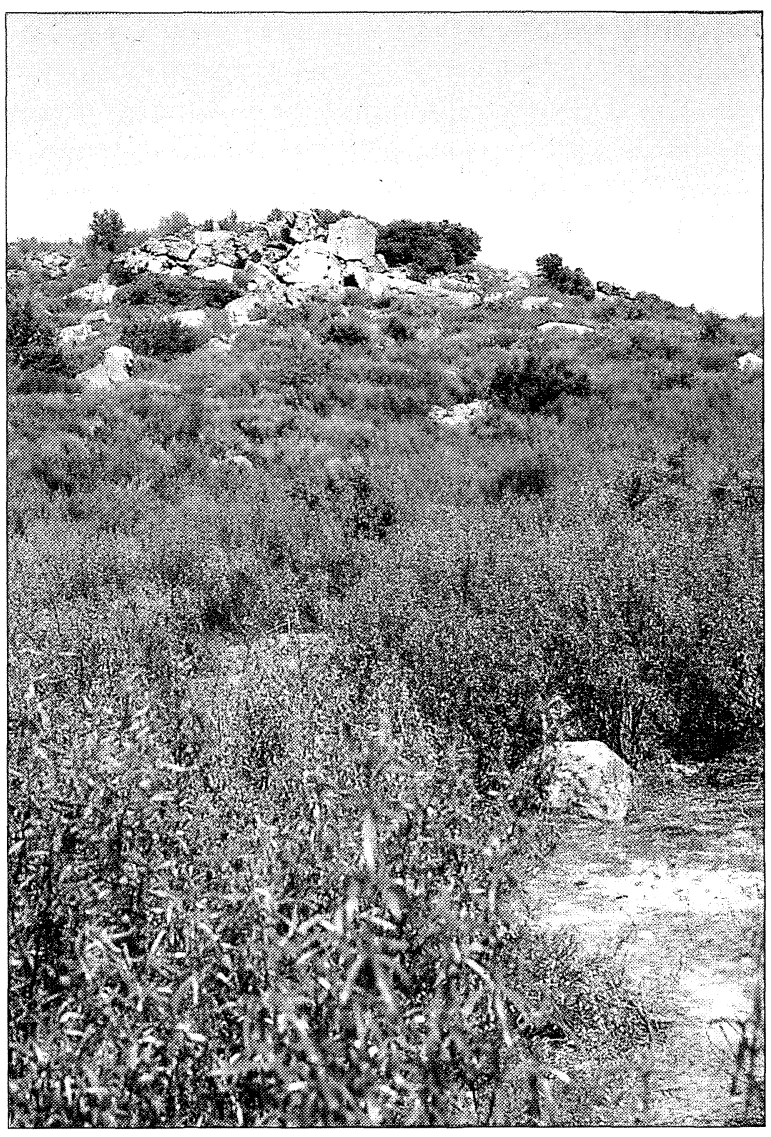

Lám.VI. Monte de El Pedroso (Trabazos deAliste, Zamora). La entrada a la cavidad con grabados esquemáticos se halla bajo el bloque granítico más sobresaliente, en el centro de la fotografía.

cámara y en mucha menor medida en el corredor, mientras que apenas se documenta en el exterior del monumento. En otras palabras, la pintura o el grabado se concentran y se hacen más complejos en los sectores más "privados" de esas construcciones donde por otra parte se depositan la mayor parte de los restos humanos-, por lo que cabe inferir que esas manifestaciones artísticas estarían dirigidas hacia una audiencia muy restringida (2). Un segundo aspecto a tener en cuenta es que algunas de las imágenes del Arte Esquemático reflejen estados alterados de la conciencia, provocados bien por la ingestión de estupefacientes o debidos a otras causas. Estos motivos incluyen seres humanos de cuerpos exage-

(2) Al margen de la coincidencia genérica entre megalitos y ciertas estaciones esquemáticas con respecto a la restricción de acceso, es interesante mencionar que en el abrigo de El Pedroso es precisamente en su divertículo interno donde se hallan los grabados más complejos. 
radamente alargados, figuras con líneas irradiando de su cabeza (Fig. 3) y animales o antropomorfos dibujados a muy pequeña escala, elementos de una visión subjetiva que han sido identificados en trabajos en curso efectuados por Thomas Dowson (comunicación personal Universidad de Southampton; Garrido, 1997). Esta hipótesis que, debemos recordarlo, es aplicable sólo a ciertas representaciones adquiere una nueva verosimilitud por el hallazgo de semillas dePapaver somniferum (amapola del opio) en el nivel II de Buraco da Pala (Ramil yAira, 1993).

\section{CONCLUSIONES}

Una vez recorrido esa especie de transecto imaginario, extendiéndose desde el área nuclear de los petroglifos galaicos hasta las comarcas con arte esquemático más próximas al Noroeste, es el momento adecuado para derivar algunas conclusiones. Una primera -y muy relevante- es que no se puede tratar los grupos artísticos prehistóricos como entes monolíticos, ajenos al paso del tiempo, a las dinámicas locales o a las influencias externas. En el caso del ciclo galaico hemos podido constatar como sus manifestaciones se integraban en una concepción del paisaje determinada y como ésta se modificaba en las áreas periféricas de su distribución, e igualmente el contraste radical en cuanto a emplazamiento y -verosímilmente- significado con el grupo esquemático. No creemos que, en oposición a este último, los petroglifos gallegos tuviesen una motivación puramente pragmática, pues su vocabulario gráfico está henchido de simbolismo y muy probablemente habría poseído un carácter polisémico, lo que no es óbice para que, al menos en apariencia, estuviese ligado a las pautas de movimiento a través del territorio. Ya en los límites de su área de expansión, con un repertorio temático más reducido, sus características básicas parecen cambiar: algunos paneles se localizan en lugares adecuados para llevar a cabo ceremonias, en tanto que la modificación de su relación con la topografía local pone de manifiesto un uso diferente del espacio.

Sólo en el sur, en torno al estuario del Miño, observamos una abundante mezcla de rasgos estilísticos propios de los grupos galaico y esquemático y únicamente las incertidumbres en cuanto a la cronología, junto con la escasez de análisis espaciales exhaustivos de conjuntos rupestres ponen límites a la profundidad de nuestro análisis. Parece de todos modos que en un número de estaciones próximas a la presente frontera luso-galaica tiene lugar cierto solapamiento de ambos ciclos artísticos, y es precisamente en esta zona o sus inmediaciones donde constatamos alteraciones en las pautas genéricas de ocupación del territorio.

Por su parte, elArte Esquemático no puede ofrecer un contraste más dramático con los petroglifos galaicos: los lugares donde hace su aparición son relativamente marginales respecto a las áreas de asentamiento y probablemente tenían un carácter muy especializado y/o una audiencia restringida. Esto último puede deducirse del propio emplazamiento de las estaciones y de las afinidades que poseen los motivos mismos.

En los primeros compases de este artículo sugeríamos tímidamente que los dos ciclos artísticos cuyas relaciones hemos estado analizando podrían ligarse con otras tantas dinámicas generales en la prehistoria ibérica, atlántica y mediterránea. Creemos que el contraste entre los grupos galaico y esquemático va más allá de las cuestiones estilísticas y afecta a otros asuntos, incluyendo la propia actitud ante el entorno y el emplazamiento de los espacios rituales. Si esto es así, entonces la diferenciación entre ambas provincias artísticas tiene un interés más profundo, por lo que supone de via de acceso a dos Weltanschauungen que atraviesan la prehistoria reciente de la Península Ibérica.

\section{AGRADECIMIENTOS}

El trabajo de campo fue financiado por la British Academy y la Society of Antiquaries. Viajes relacionados con la preparación del proyecto fueron subvencionados por el British Council y la Universidad de Reading; una visita previa a Portugal fue organizada porVítor y Susana Oliveira Jorge y subvencionada por la Universidad de Oporto. Queremos expresar nuestro agradecimiento a las personas que nos guiaron y discutieron sus interpretaciones con nosotros: Julian Bécares Pérez, Antonio Martinho Baptista, Germán Delibes de Castro, Julio Fernández Manzano, Paula Mota Santos, Maria de Jesus Sanches, Jorge de Santiago y Ricardo Martín Valls. Hemos contraído una especial deuda de gratitud con Javier Costas Goberna, quien nos condujo a muchos petroglifos emplazados en las comarcas limítrofes de Galicia y Portugal, proporcionándonos además valiosas informaciones en una afortunada combinación de francés, inglés, castellano y gallego. Lara Alves y Thomas Dowson nos permi-

T. P., 56, n. ${ }^{\circ} 1,1999$ 
tieron usar sus investigaciones en curso de realización. El borrador de este trabajo fue revisado por Victoria Villoch Vázquez a quien también agradecemos sus sugerencias. Los dibujos fueron realizados por Anxo Rodríguez Paz.

\section{BIBLIOGRAFÍA}

Acosta, P. (1968): La pintura rupestre esquemática en España. Memorias del Seminario de Prehistoria y Arqueología, 1. Salamanca.

Acuña, F.; Criado, F.; Vázquez, J.M.; Soto, M.J.; Luaces, J.; Penedo, R. y Meijide, G. (1987): Catalogación de yacimientos prerromanos del ayuntamiento de Santiago. Xunta de Galicia, Arqueoloxía/Investigación, 3. Santiago de Compostela.

Almagro Gorbea, M. (1995): "Ireland and Spain in the Bronze Age”. En J. Waddell y E. Shee Twohig (eds.): Ireland in the Bronze Age. Stationery Office. Dublin: 136-48.

Aparicio Casado, B. (1986): "Sobre el supuesto ídolo calcolítico de A Caeira (Poio - Pontevedra)". Pontevedra Arqueológica, 2: 65-81.

BÉCARES PÉREZ, J. (1991): "La pintura rupestre en la provincia de Salamanca". En Del Paleolítico a la Historia. Junta de Castilla y León. Salamanca: 61-79.

Blasco Bosqued, Ma. C. y Baena Preysler, J. (1996): “El yacimiento de Las Carolinas y la cerámica simbólica campaniforme. Algunos datos para su interpretación". En A. Moure Romanillo (ed.): 'El hombre fósil' 80 años después. Universidad de Cantabria. Santander: 417-46.

BRADLEY, R. (1997): Rock art and the prehistory of Atlantic Europe. Routledge. London.

- (1998): "Invisible warriors: Galician weapon carvings in their Iberian context". En R. Fábregas (ed.): A Idade do Bronce en Galicia: novas perspectivas. Ediciós do Castro. A Coruña: 243-258.

Bradley, R.; Criado, F. y FÁBregas, R. (1995): "Rock art and the prehistoric landscape of Galicia". Proceedings of the Prehistoric Society, 61: 341-70.

BRADLEY, R. y FÁBREGAS VALCARCE, R. (1995): "El silencio de las fuentes: prácticas funerarias en la Edad del Bronce del Noroeste y su contexto europeo". Complutum, 6 : 153-166.

- (1996): "Petroglifos gallegos y arte esquemático: una propuesta de trabajo". En A. Querol y T. Chapa (eds.): Homenaje al prof. M. Fernández Miranda. Complutum Extra 6.II: 103-10.

BREUIL, H. (1933): Les peintures rupestres schématiques de la peninsule Ibèrique, vol. 1. Imprimerie de Lagny. Paris.

Bueno Ramírez, P. (1992): "Les plaques décorées alentéjaines: approche de leur étude et analyse". L'Anthropologie, 96(2-3): 573-604.
Bueno Ramírez, P. y Balbín Behrmann, R. (1992): “L'art mégalithique dans la péninsule Ibérique: une vue d'ensemble". L'Anthropologie, 96: 499-572.

Carballo, X.; Fábregas, R.; Ledo, M. y Constenla, X. (e.p.): "Dos nuevos yacimientos con cerámica tipo Penha en el valle del Miño". Zephyrus.

CHAPMAN, R. (1991): La formación de las sociedades complejas. El Sureste de la Península Ibérica en el marco del Mediterráneo Occidental. Crítica. Barcelona.

Coles, J. y Harding, F. (1979): The Bronze Age in Europe. Methuen. London.

Comendador Rey, B. (1997): "Las representaciones de armas y sus correlatos metálicos". En F.J. Costas Goberna y J.M. Hidalgo Cuñarro (eds.): Los motivos de fauna y armas en los grabados prehistóricos del continente Europeo. Vigo: 113-30.

Costas Goberna, F.J. e Hidalgo Cuñarro, J.M. (1995): "Los petroglifos del término municipal de Vigo y su comarca: apuntes sobre el arte rupestre en la costa sur de Galicia y el Bajo Miño". Boletín del Instituto de Estudios Vigueses, 1: 29-95.

Costas Goberna, F.J. y Novoa Alvarez, P. (1993): Los grabados rupestres de Galicia. Monografías, 6. Museu Arqueolóxico e Histórico. A Coruña.

Costas, F.J.; Albo, J.M. y Ferreira, F. (1989): "El petroglifo del monte Tetón (Tomiño) grupo 1: levantamiento de calcos y fotografía". Castrelos, 1-2: 27-49.

Costas, F.J.; Domínguez, M. y Rodríguez, J.M. (1991): "Nuevos grabados rupestres en el litoral sur de la Ría de Vigo". Castrelos, 3-4: 117-40.

Costas, F.J.; Novoa, P. y Sanromán, J.A. (1995): "Sta. María de Oia. Sus grabados rupestres". XXII Congreso Nacional de Arqueología, Vigo (1993) vol. 2: 131136.

Costas, F.J.; Hidalgo, J.M.; Novoa, P. y PeÑa, A. (1997a): "Las representaciones de armas en el grupo galaico de arte rupestre". En F.J. Costas Goberna y J.M. Hidalgo Cuñarro (eds.): Los motivos de fauna y armas en los grabados prehistóricos del continente Europeo. Asociación Arqueológica Viguesa. Vigo: 85-112.

- (1997b): "Aproximación a las representaciones de cuadrúpedos en el grupo galaico de arte rupestre". En F.J. Costas Goberna y J.M. Hidalgo Cuñarro (eds.): Los motivos de fauna y armas en los grabados prehistóricos del continente Europeo. Asociación Arqueológica Viguesa. Vigo: 53-84.

Criado, F.; Fábregas, R. y Santos, M. (e.p.): "Paisaje y representación en la Edad del Bronce: la descodificación del arte". En Ruiz-Gálvez, M. (ed.): Edad del Bronce. Crítica. Barcelona.

Delibes, G.; Herrán, J.L.; De Santiago, J. y del Val, J. (1995): "Evidence for social complexity in the copper age of the northern meseta". En K.T. Lilios (ed.): The Origins of Complex Societies in Late Prehistoric Iberia. International Monographs in Prehistory, 8. Ann Arbor: 44-63. 
Eogan, G. (1990): "Irish megalithic tombs and Iberia. Contrasts and comparisons". Probleme der Megalithgräberforschung. De Gruyter. Berlin: 113-37.

Esparza Arroyo, A. (1977): "El castro zamorano de El Pedroso y sus insculturas". Boletín del Seminario de Estudios de Arte y Arquelogía, 43: 27-39.

FÁbregas Valcarce, R. (ed.) (1998): A Idade do Bronce en Galicia: novas perspectivas. Cadernos do Seminario de Sargadelos 77. A Coruña.

Fábregas Valcarce, R. y Penedo Romero, R. (1994): "Petroglifos e arte das cistas do Noroeste". Trebaruna, 3 : 5-21.

Fábregas Valcarce, R. y Ruiz-GálVez, M. (1997): “El Noroeste de la Península en el III y II ${ }^{\circ}$ Milenios. Propuestas para una síntesis“. Homenaje a la prof. M. Gil Mascarell, vol 2, Universidad de Valencia. Valencia: 191-216.

G.A.T.T. (1996): "Aporte sobre vellos cultos no Monte de Chamorro (Ferrol)". Anuario Brigantino, 19: 119-122.

García Alén, A. y Peña Santos, A. (1980): Grabados rupestres de la Provincia de Pontevedra. Fundación Barrié. Pontevedra.

García Arranz, J.J. (1990): La pintura rupestre esquemática en la comarca de Las Villuercas, Cáceres. Universidad de Salamanca. Salamanca.

Garrido Pena, R. (1997): "Bell Beakers in the Southern Meseta of the Iberian Peninsula: socioeconomic context y new data“. Oxford Journal of Archaeology, 16: 187-209.

Gómez BARrera, J. (1992): "Manifestaciones de la facies esquemática en el centro y norte de la Península Ibérica“. Espacio, Tiempo y Forma, 5: 231-64.

Gutiérrez GonzÁlez, J.A. y Avelló Álvarez, J.L. (1986): Las pinturas rupestres esquemáticas de Sésamo, Vega de Espinareda, León. Centro de Investigación y Museo de Altamira, Monografías, 12. Madrid.

Harbison, P. (1967): "Mediterranean and Atlantic elements in the Early Bronze Age of northern Portugal and Galicia“. Madrider Mitteilungen, 8: 100-22.

HARRISON, R. (1974): "Ireland and Spain in the Early Bronze Age". Journal of the Royal Society of Antiquaries of Ireland, 104: 52-73.

Hidalgo Cuñarro, J.M. y Costas Goberna, F.J. (1984-85): "El petroglifo inédito de armas de "Auga da Laxe" (Vincios-Gondomar)“. Brigantium, 5: 227-241.

JoRgE, S.O.(1993): "O povoado de Castelo Velho (Freixo de Numâo, Vila Nova de Foz Côa) no contexto da Préhistória Recente do Norte de Portugal “. $1^{\circ}$ Congresso de Arqueologia Peninsular (Oporto 1993), 1: 145-221. Oporto.

- (1994): "Colónias, fortificações, lugares monumentalizados. Trajectória das concepções sobre um tema calcolitico peninsular". Revista da Facultade de Letras, 11: 447-546.

Jorge, V.O. y Jorge, S.O. (1991): "Figurations humaines préhistoriques du Portugal: dolmens ornés, abris peints, rochers gravés, statues-menhirs". Revista da Facultade de Letras, 8: 341-84.

Martí, B. y HeRnández, M.S. (1988): El Neolitic Valencià. Arte rupestre i cultura material. Servei d'Investigació Prehistòrica de la Diputació. Valencia.

MÉndez FernándeZ, F. (1998): "Definición y análisis de poblados de la Edad del Bronce en Galicia“. En R. Fábregas (ed.): A Idade do Bronce en Galicia: novas perspectivas. Cadernos do Seminario de Sargadelos, 77. A Coruña: 153-189.

PeÑa Santos, A. (1979): "Notas para una revisión de los grabados rupestres de 'O Castriño' en Conxo". El Museo de Pontevedra, 33: 3-32.

Peña Santos, A. y Rey García, J. (1993): "El espacio de la representación. El arte rupestre galaico desde una perspectiva territorial“". Revista de Estudios Provinciais, 10: 11-50.

- (1998): "Perspectivas actuales en la investigación del arte rupestre galaico". En R. Fábregas (ed.): A Idade do Bronce en Galicia: novas perspectivas. Cadernos do Seminario de Sargadelos 77. A Coruña: 221-241.

Ramil Rego y Aira Rodríguez, M.J. (1993): “A palaeocarpological study of Neolithic y Bronze Age levels of the Buraco da Pala rock-shelter (Bragança, Portugal)“. Vegetation History \& Archaeobotany, 2: 163-72.

Ripoll Perelló, E. (1990): "Acerca de algunos problemas del arte postpaleolítico en la Península Ibérica“. Espacio, Tiempo y Forma, 3: 71-104.

Ruiz-Gálvez, M. (1978): "El tesoro de Caldas de Reyes". Trabajos de Prehistoria, 35: 173-86.

SANChes, M.J. (1996a): Ocupação pré-histórica do Nordeste de Portugal. Fundación Rei Afonso Henriques. Zamora.

- (1996b): "Passos / Santa Comba Mountain in the context of the late prehistory of northern Portugal". World Archaeology, 28: 220-30.

- (1997): Pré-história recente de Trás-os-Montes e Alto Douro. Sociedade Portuguesa de Antropologia e Etnologia. Oporto.

Santos Estévez, M. (1996): "Los grabados rupestres de Tourón y Redondela-Pazos de Borbén como ejemplos de un paisaje con petroglifos". Minius, 5: 13-40.

Shee Twohig, E. (1981): The megalithic art of western Europe. Clarendon Press. Oxford.

Silva, E.J.L. da y CunHA, A.M.L. da (1986): "As gravuras rupestres do Monte da Laje (Valença)". Arqueologia, 13: $143-58$

VÁzQuez Varela, J.M. (1990): Petroglifos de Galicia. Servicio de Publicacións da Universidade. Santiago de Compostela.

- (1996): "El petroglifo de Auga de Laxe 1 (Gondomar, Pontevedra) y la sociedad del comienzo de la edad del bronce en el noroeste de la península Ibérica". Gallaecia, 16: 201-20.

T. P., 56, n. $^{\circ} 1,1999$ 